\title{
Aqueous electrolytes: retrieving latent fingermarks from crumpled aluminum foil
}

\author{
Om Prakash Jasuja \\ Kulvir Singh \\ Department of Forensic Science, \\ Punjabi University, Patiala, \\ Punjab, India
}

This article was published in the following Dove Press journal:

Research and Reports in Forensic Medical Science

14 December 2016

Number of times this article has been viewed

Correspondence: Om Prakash Jasuja Department of Forensic Science, Punjabi University, Patiala I47002, Punjab, India

Email opjasuja@gmail.com
Abstract: Development of latent fingermarks on the flat surface of aluminum foil is an easy task. Fingermark powders, powder suspension, and cyanoacrylate fuming are applied routinely and work well. Development of latent fingermark on crumpled foil is a bit of a challenge. Depending upon the depth and nature of the folds, the presently used techniques may not help to develop fingermarks in their full form. In the present study, an attempt has been made to resolve this issue by using aqueous electrolytes. The results obtained by using the proposed technique were compared with powder, powder suspension, and cyanoacrylate fuming techniques. The proposed technique was found to be better than that of other techniques in the case of crumpled aluminum foil.

Keywords: crime scene, latent fingermarks, nonporous surfaces, crumpled aluminum foil, aqueous electrolytes

\section{Introduction}

Criminals often leave their signed confessions, in the form of latent fingermarks, on different surfaces at the crime scene. ${ }^{1}$ Over the years, numerous techniques have been suggested to develop latent fingermarks on different types of surfaces, generally classified as porous, semiporous, and nonporous. ${ }^{2}$ Aluminum foil has gained popularity in the wrapping and food packaging industries, and it may be found at the crime scene as a flat surface, folded piece or in a crumpled mass. Fingermark powders, powder suspension, cyanoacrylate fuming, ${ }^{3}$ scanning Kelvin probe (SKP) ${ }^{4}$ electropolymerization, ${ }^{5}$ electrodeposition of metal nanoparticles, ${ }^{3,6}$ columnar thin film deposition, ${ }^{7}$ thermal visualization, ${ }^{8}$ luminescent carbon dot, ${ }^{9}$ silica gel $\mathrm{G},{ }^{10}$ and aqueous electrolytes ${ }^{11,12}$ have been reported to develop latent fingermarks on nonporous surfaces.

Among these techniques, the use of aqueous electrolytes to develop latent fingermarks is a comparatively newer technique and has been proven to be useful in developing latent fingermarks on different types of surfaces. ${ }^{11,12}$ Aqueous electrolyte is any substance that when dissolved in water forms charged ions. ${ }^{13}$

In the present study, aqueous electrolytes have been used to develop latent fingermarks on crumpled aluminum foil. The results have been compared with those produced with three commonly used techniques: fingermark powder, powder suspension, and atmospheric cyanoacrylate fuming.

\section{Materials and methods}

\section{Aluminum foil}

Two rolls of aluminum foil (thickness: 11 microns and 18 microns) were purchased from local stores and used in the current study. 


\section{Acquisition of latent fingermarks}

Natural fingermarks were deposited on crumpled aluminum foil (total 100; 25 samples per technique) in the current study as per the International Fingerprint Research Group (IFRG) guidelines. ${ }^{14}$ The volunteers were informed verbally about the noninvasive nature of the experiment and requested to pull out foil from the rolls and make crumpled masses with bare hands (Figure 1). The crumpled masses (100 samples) were carefully removed by KS with gloved hands, and the deposited fingermarks left unprocessed for 1 day. The wooden handle of a knife and an ice pick were wrapped with foil by the volunteers. The wrapped, crumpled foil was then carefully removed from the wooden handle by KS. Five volunteers, including three males and two females, were asked (from the department students and staff), irrespective of their donor capabilities, for the deposition of natural fingermarks. The age of the volunteers ranged from 25 to 48 years. The volunteers were asked to wash their hands properly with soap and allowed to do natural activities for 4 hours before the deposition of fingermarks on the foil.

\section{Chemicals}

Fused calcium chloride $\left(\mathrm{CaCl}_{2} ; 95 \%\right.$ extra pure), potassium permanganate $\left(\mathrm{KMnO}_{4}\right.$; analytical reagent $[\mathrm{AR}]$ grade $)$, and liquid detergent (neutral) were procured from Loba Chemie (Mumbai, India). Activated charcoal powder was procured from SDFCL, Ltd. (Mumbai, India), and used in the study.

\section{Preparation of electrolytes}

Separate solutions of fused $\mathrm{CaCl}_{2}$ and $\mathrm{KMnO}_{4}$ were prepared in distilled water $\left(\mathrm{CaCl}_{2} 8 \% \mathrm{w} / \mathrm{v}\right.$ and $\left.\mathrm{KMnO}_{4} 4 \% \mathrm{w} / \mathrm{v}\right)$, as suggested by Jasuja et al, ${ }^{12}$ and mixed. It has been shown that $6 \%-8 \% \mathrm{w} / \mathrm{v} \mathrm{CaCl}_{2}$ was the optimized concentration to develop latent fingermarks on aluminum. Hence, $\mathrm{KMnO}_{4}$ was experimented with $\mathrm{CaCl}_{2}(8 \%)$, and different concentrations
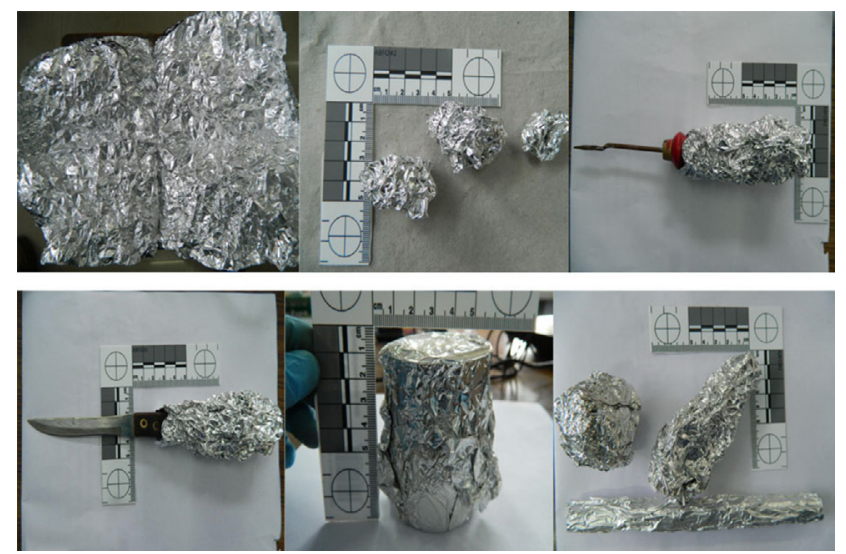

Figure I The mode of natural fingermarks collection on different foil forms. of $\mathrm{KMnO}_{4}$ ranging from $1 \%$ to $5 \%$ (with an interval of $1.0 \%$ ) were tried to get optimized concentration.

\section{Fingermarks development procedure}

The following four techniques were used individually to develop the latent fingermarks on the crumpled foils (and the fingermarks of the same person were treated by all the techniques to avoid donor intervariability):

1. Immersion in aqueous electrolytes for 30 minutes (Figure 2A).

2. Brushing with activated charcoal powder (used as a dry fingermark powder).

3. Spraying with charcoal powder-based powder suspension. ${ }^{15} 15 \mathrm{~g}$ of activated charcoal powder and $1-2 \mathrm{~mL}$ of liquid detergent were added to $100 \mathrm{~mL}$ of water and stirred until thoroughly mixed. Excess powder was detached by water sprayed gently above the developed fingermarks.

4. Cyanoacrylate fumed in an atmospheric cabinet. ${ }^{3} 3 \mathrm{~g}$ of cyanoacrylate (Foster + Freeman Ltd., Evesham, UK) was placed in a fuming cabinet at $80 \%( \pm 2 \%)$ of relative humidity and at $120^{\circ} \mathrm{C}$ for $\sim 15-30$ minutes.

The developed fingermarks were photographed with a Nikon ${ }^{\circledR}$ Coolpix L120 (Tokyo, Japan), Semi SLR digital camera. The third-level details of a fingermark were examined under a stereomicroscope at $40 \times$ by KS.

\section{Assessment of developed fingermarks}

The IFRG grading scheme ${ }^{14}$ was followed for the assessment of the developed fingermarks (Table 1), and the developed fingermarks were graded by KS (both with the naked eye and using a stereomicroscope) in order to maintain a standard objectivity and uniformity and avoid interobserver variations.

\section{Results}

For aqueous electrolytes, the optimized concentration of $\mathrm{CaCl}_{2}(8 \%)$ was tested with $1 \%-5 \%$ of $\mathrm{KMnO}_{4}$ in a 1:1 ratio. Accordingly, the grade of developed fingermarks was assigned a value by KS, as per the IFRG guidelines. ${ }^{14}$ For example, a solution of $8 \% \mathrm{CaCl}_{2}$ and $2 \% \mathrm{KMnO}_{4}$ in a 1:1 ratio gave grade 2 of the developed latent fingermarks (Table 2, Figure 2B). Of note, the split latent fingermarks were developed with $1 \%-5 \%$ of $\mathrm{KMnO}_{4}$ and $8 \% \mathrm{CaCl}_{2}$ in a $1: 1$ ratio to get the optimized concentration of $\mathrm{KMnO}_{4}$ (Table 2, Figure 2C).

A mixture of $8 \%$ solution of $\mathrm{CaCl}_{2}$ and $4 \%$ solution of $\mathrm{KMnO}_{4}$ (ratio 1:1) was found to be most effective to develop 
A

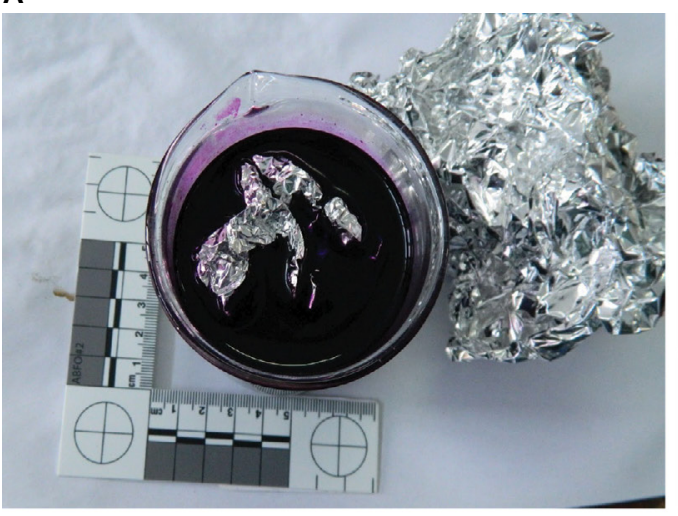

B

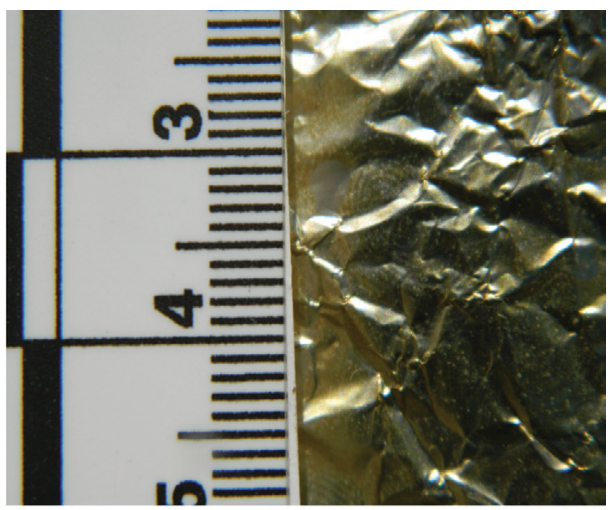

C

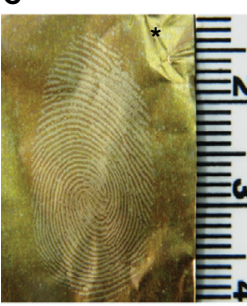

(a)

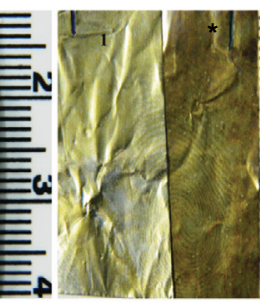

(b)

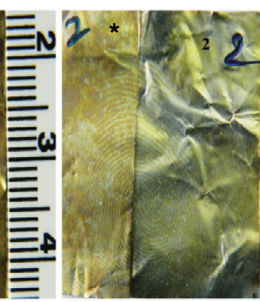

(c)

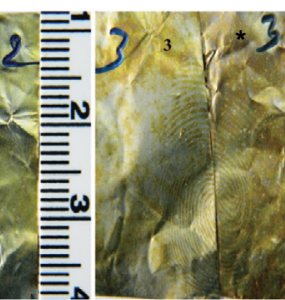

(d)

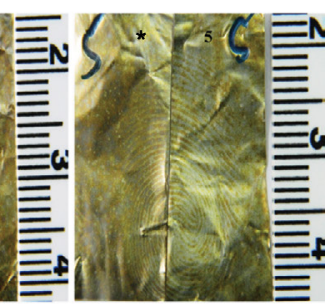

(e)

Figure 2 (A) The crumpled foil immersed in aqueous electrolyte solution. (B) The developed latent fingermark of grade 2 on crumpled aluminum foil with the solution of $2 \% \mathrm{KMnO}_{4}$ and $8 \% \mathrm{CaCl}_{2}$ (with I:I ratio). (C) The developed latent (split) fingermarks on aluminum foil with the solutions of $1 \%-5 \% \mathrm{KMnO}_{4}$ and $8 \% \mathrm{CaCl}_{2}$ (with I:I ratio). *Represents the development of latent fingermarks with the concentration of: $4 \% \mathrm{KMnO}_{4}$ and $8 \% \mathrm{CaCl}_{2}:(\mathbf{a}) 4 \% \mathrm{KMnO}_{4}$ and $8 \% \mathrm{CaCl}_{2}$ (b) $(\mathrm{I}) \quad 1 \% \mathrm{KMnO}_{4}$ and $8 \% \mathrm{CaCl}_{2}$ (c) (2) $2 \% \mathrm{KMnO}_{4}$ and $8 \% \mathrm{CaCl}_{2}$ (d) (3) $3 \% \mathrm{KMnO}_{4}$ and $8 \% \mathrm{CaCl}_{2}$ (e) (5) $5 \% \mathrm{KMnO}_{4}$ and $8 \% \mathrm{CaCl}_{2}$. (I)-(5) in (b)-(e) are the respective serial numbers.

Table I The IFRG guidelines

\begin{tabular}{ll}
\hline Grade & Details observed \\
\hline 0 & No development \\
I & $\begin{array}{l}\text { Signs of contact but less than } \mathrm{I} / 3 \text { of mark with continuous } \\
\text { ridges }\end{array}$ \\
2 & I/3-2/3 of mark with continuous ridges \\
3 & More than $2 / 3$ of mark with continuous ridges, but not quite a \\
& perfect mark \\
\hline
\end{tabular}

Note: Data from a previous study. ${ }^{14}$

Abbreviation: IFRG, International Fingerprint Research Group.

Table 2 The range of different concentrations of $\mathrm{KMnO}_{4}$ tested with $\mathrm{CaCl}_{2}$ and accordingly assigned grade of developed fingermark

\begin{tabular}{lllll}
\hline $\begin{array}{l}\text { Serial } \\
\text { no }\end{array}$ & $\begin{array}{l}\text { Calcium } \\
\text { chloride (w/v) } \\
\text { (optimized } \\
\text { concentration) }\end{array}$ & $\begin{array}{l}\text { Potassium } \\
\text { permanganate } \\
(\mathbf{w} / \mathbf{v})\end{array}$ & $\begin{array}{l}\text { Solution } \\
\mathrm{CaCl}_{2}: \\
\mathbf{K M n O}_{4}\end{array}$ & $\begin{array}{l}\text { Grade of } \\
\text { developed } \\
\text { fingermark }\end{array}$ \\
\hline $\mathrm{I}$ & $8 \%$ & $\mathrm{I} \%$ & $\mathrm{I}: \mathrm{I}$ & 2 \\
2 & $8 \%$ & $2 \%$ & $\mathrm{I}: \mathrm{I}$ & 2 \\
3 & $8 \%$ & $3 \%$ & $\mathrm{I}: \mathrm{I}$ & 3 \\
4 & $8 \%$ & $4 \%$ & $\mathrm{I}: \mathrm{I}$ & 4 \\
5 & $8 \%$ & $5 \%$ & $\mathrm{I}: \mathrm{I}$ & 3 \\
\hline
\end{tabular}

latent prints of very high quality (grade 4 ) at room temperature $\left(20^{\circ} \mathrm{C}-24^{\circ} \mathrm{C}\right.$; Figures 3 and 4$)$.

The powdering technique could develop only partial prints of grade 2 (Figure 5).

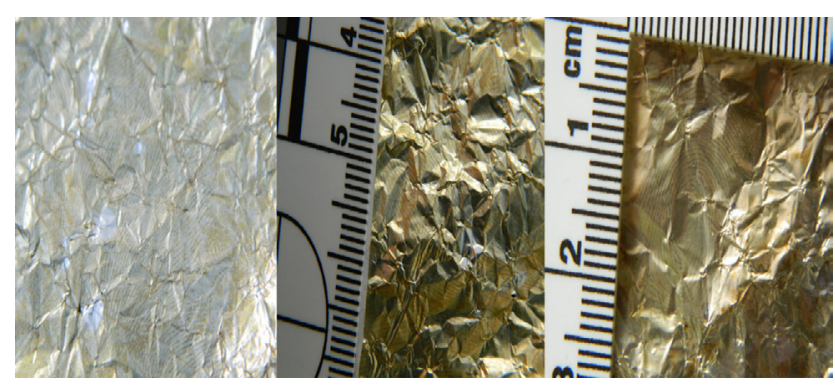

Figure 3 The developed latent fingermark of grade 4 on crumpled aluminum foil with the solution of $4 \% \mathrm{KMnO}_{4}$ and $8 \% \mathrm{CaCl}_{2}$ (with I:I ratio).

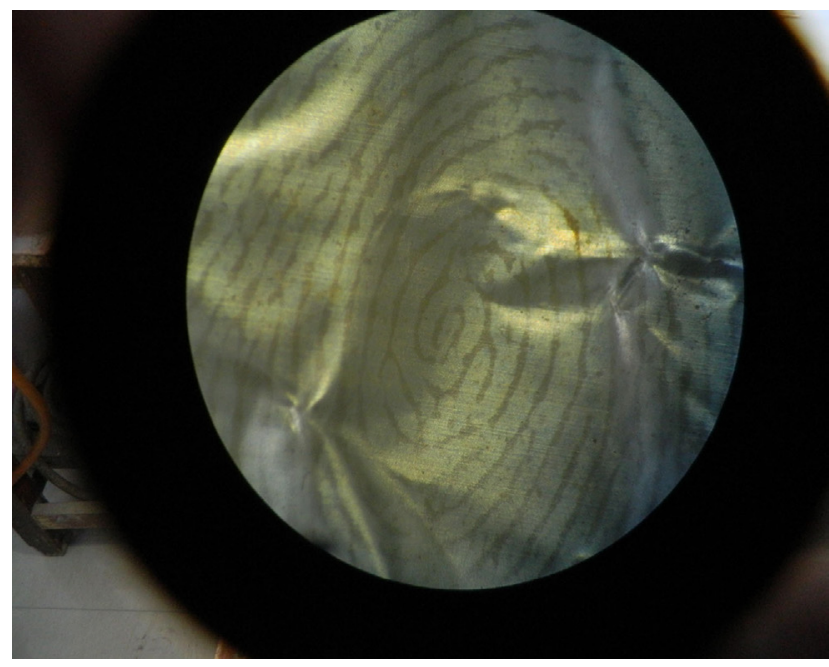

Figure 4 The developed latent fingermark of grade 4 by aqueous electrolytes on crumpled aluminum foil under stereomicroscope at $40 \times$. 


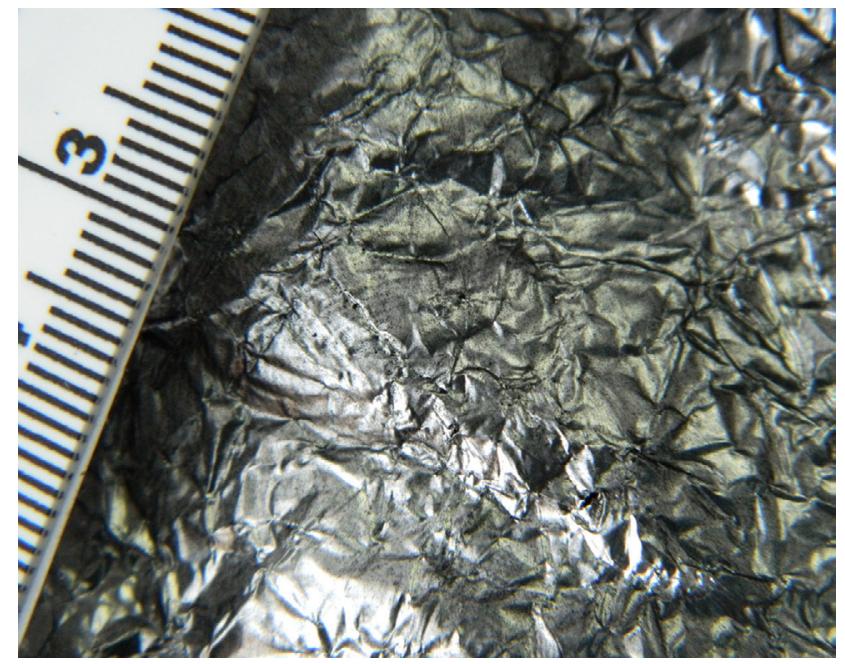

Figure $\mathbf{5}$ The developed latent fingermark of grade 2 on uncrumpled aluminum foil with the powder method.

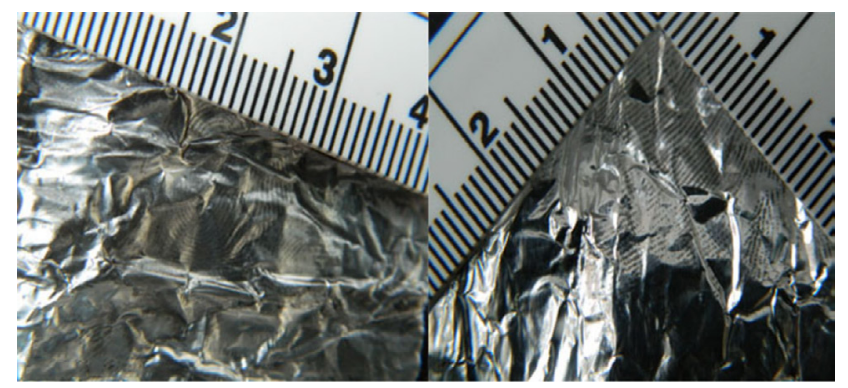

Figure 6 The developed latent fingermark of grade 3 on uncrumpled aluminum foil with the powder suspension.

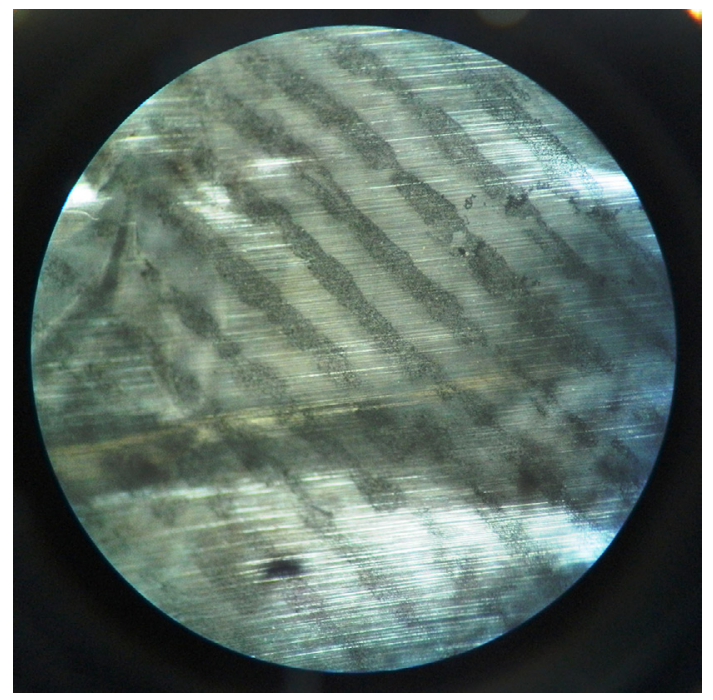

Figure 7 The developed latent fingermark of grade 3 with the powder suspension on uncrumpled aluminum foil under stereomicroscope at $40 \times$.

The powder suspension technique provided better results than the powdering technique (Figures 6 and 7).

Results produced by the atmospheric cyanoacrylate fuming technique were better than those by the powdering and

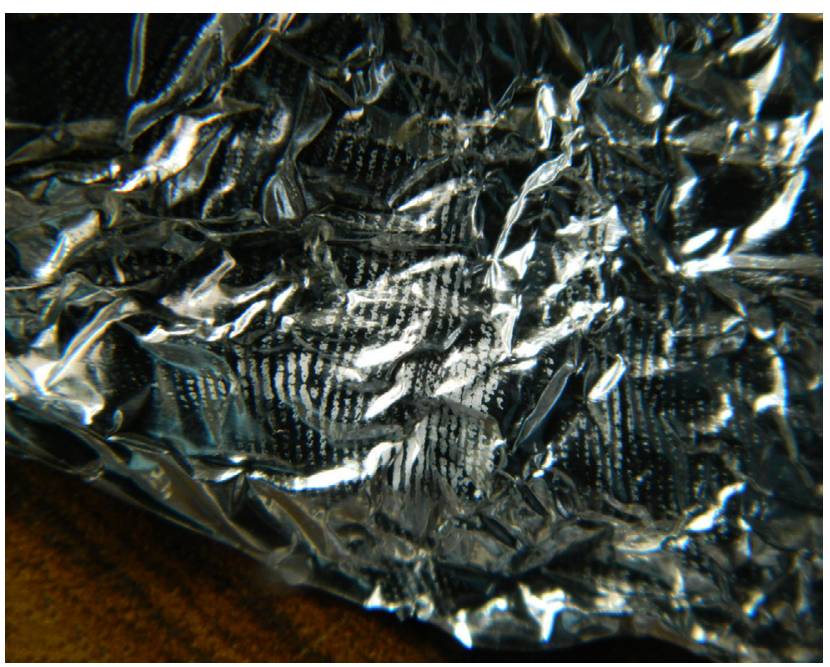

Figure $\mathbf{8}$ The developed latent fingermark of grade 3 on crumpled aluminum foil (outer side) with the cyanoacrylate fuming.

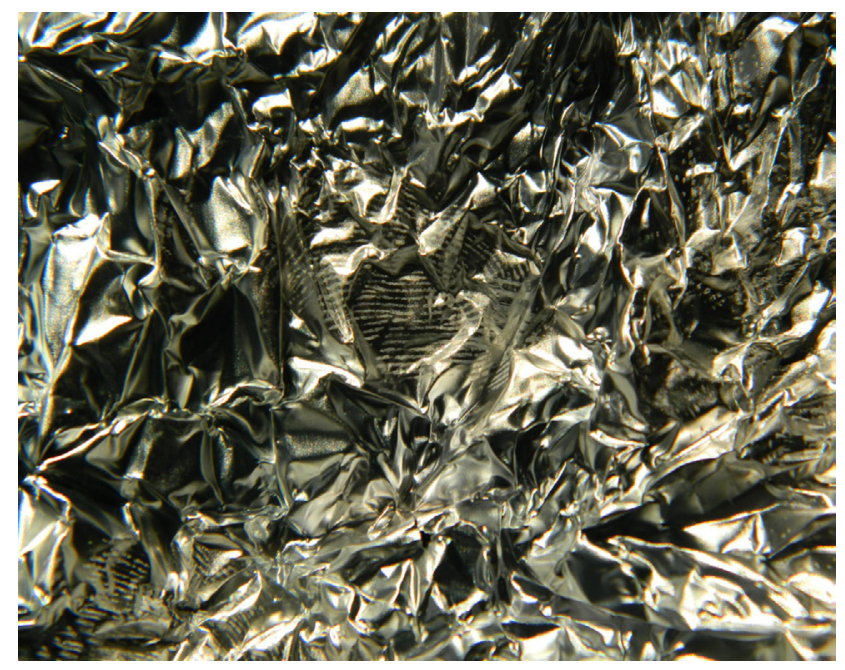

Figure 9 The completely developed latent fingermark of grade 4 on uncrumpled aluminum foil with the cyanoacrylate fuming.

powder suspension technique. As can be seen in Figure 8, the exposed portions of the foil have clearly developed prints, whereas the unexposed portions (insides of creases and folds) remained undeveloped. The uncrumpling of foil and further exposure to the fumes have provided further details (Figures 9 and 10).

From this comparative study (Table 3 ), it was found that aqueous electrolytes had developed the latent fingermarks on 21 out of 25 samples of crumpled aluminum foil; cyanoacrylate fuming had developed 17 out of 25 ; powder suspension had developed 12 out 25; and powdering had developed 7 out of 25 samples (Figure 11). Therefore, based on the comparative study, the effectiveness of techniques was found in the following order:

Aqueous Electrolytes $>$ Atmospheric Cyanoacrylate Fuming $>$ Powder suspension $>$ Powder technique. 


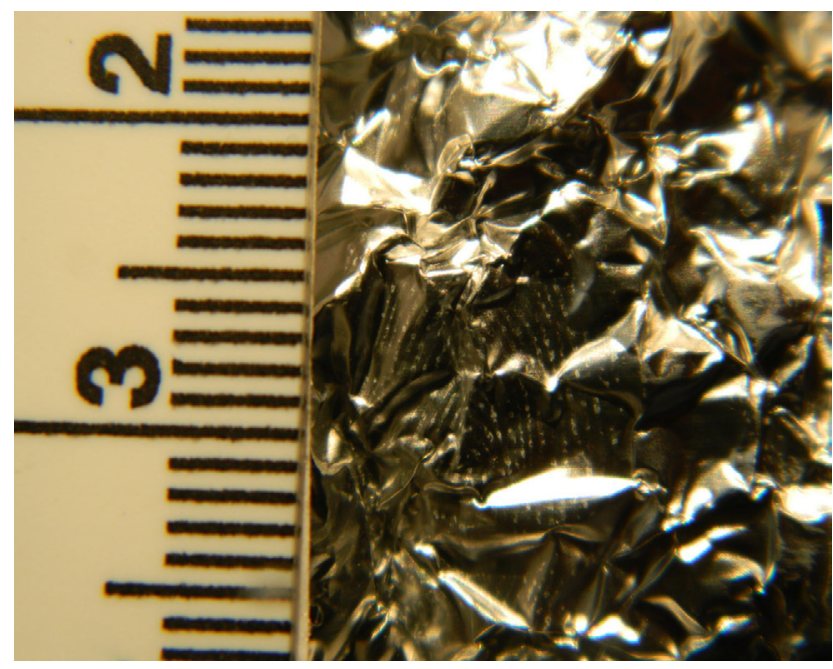

Figure 10 The partially developed latent fingermark of grade 3 on uncrumpled aluminum foil with the cyanoacrylate fuming.

Number of samples with developed fingermarks

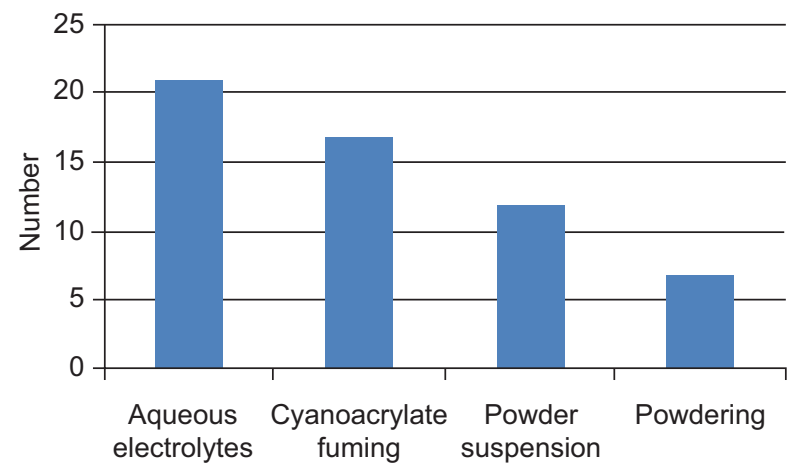

Figure II Depicting the results of the comparative study among mentioned techniques.

Table 3 The most common grades of developed fingermarks with four different techniques

\begin{tabular}{llll}
\hline $\begin{array}{l}\text { Serial } \\
\text { no }\end{array}$ & Technique & Foil state & $\begin{array}{l}\text { Most common } \\
\text { grade of developed } \\
\text { fingermarks }\end{array}$ \\
\hline 1 & Aqueous & Crumpled & 4 \\
& electrolyte & Uncrumpled & 4 \\
2 & Charcoal & Crumpled & 0 \\
& powder & Uncrumpled & 2 \\
3 & Powder & Crumpled & 0 \\
& suspension & Uncrumpled & 3 \\
4 & Cyanoacrylate & Crumpled (outer & 3 \\
& fuming & layer of the foil) & \\
& & Uncrumpled & 4 \\
\hline
\end{tabular}

\section{Discussion}

Various authors have proposed different techniques for the visualization of latent fingermarks on metal surfaces. ${ }^{3}$ Vacuum metal deposition prior to SKP proved to be faithful by enhancing the low SKP potential contrast between ridges and furrows. ${ }^{4}$ An electropolymerization process (of pyrrole and porphyrins) has been suggested for the development of latent fingermarks on the unfired weapons. The polymerization process occurred between furrows, leaving the residual part intact, giving a negative impression of the fingerprint. Similarly, deposition of gold or silver nanoparticles on conductive surfaces by electrochemical workstation developed the latent fingermarks. ${ }^{6}$ The different metal surfaces were treated thermally for the visualization of the latent fingermarks. The temperature was varied from $200^{\circ} \mathrm{C}$ to $750^{\circ} \mathrm{C}$ in the furnace, depending on the metal. The differential oxidation of the metal and residue results in the contrast between ridges and furrows. ${ }^{8}$ Aqueous electrolytes have recently been introduced for the development of latent fingermarks on metal surfaces. Very dilute solutions of acids and bases were first used for the development of latent fingermarks on metal surfaces. ${ }^{11}$ Later on, inorganic salts were used as aqueous electrolytes for the development of latent fingermarks on different metal surfaces. ${ }^{12}$ In the current work, the application of aqueous electrolytes has been tested for the development of latent fingermarks on the crumpled foil. When the crumpled foil is immersed in the aqueous electrolytes solution, the liquid seeps into the folds and wrinkles of the foil deeply, making latent fingermarks visible. The atmospheric cyanoacrylate fuming technique is also very useful for developing fingermarks on nonporous surfaces; however, the results with aqueous electrolytes have been found to be better than those with the atmospheric cyanoacrylate fuming technique while analyzing crumpled foil.

Photographing the developed fingermarks on crumpled foil was a challenging process. The low depth-of-field in close-up photos may need extra care. If circumstances permit, the foil could be carefully uncrumpled to get more details of the developed fingermarks. However, uncrumpling is possible only in the case of aqueous electrolyte-developed fingermarks (because of the permanency of the developed fingermarks), but was detrimental to the developed fingermarks in the powder, powder suspension, and atmospheric cyanoacrylate techniques. However, cyanoacrylate-developed fingermarks have shown better stability than the powder and powder suspension techniques.

As has been suggested, the development of latent fingermarks by aqueous electrolytes may occur because of the formation of film by depassivation of the aluminum surface by $\mathrm{CaCl}_{2} . \mathrm{KMnO}_{4}$, being a strong oxidizing agent, acts simultaneously on the film formed by $\mathrm{CaCl}_{2}$. Therefore, it alters the film by oxidizing it and colors the surface, thereby enhancing the latent fingermarks. ${ }^{12}$ 


\section{Conclusion}

The use of aqueous electrolytes to develop latent fingermarks on crumpled aluminum foil has been found to be better than the commonly used fingermark powdering, powder suspension, and atmospheric cyanoacrylate fuming techniques. The added advantage is permanency of the developed fingermarks.

\section{Acknowledgments}

The authors would like to acknowledge the help rendered by the laboratory technical staff of the Department of Forensic Science, Punjabi University, Patiala. Kulvir Singh is thankful to the University Grants Commission, New Delhi, for the award of a fellowship.

\section{Disclosure}

The authors report no conflicts of interest in this work.

\section{References}

1. Yount L. Forensic Science: From Fibers to Fingerprints. New York, NY: Chelsea House Publishers; 2007.

2. Champod C, Lennard C, Margot P, Stoilovic M. Fingerprints and Other Ridge Skin Impression (International Forensic Science and Investigation Series). Boca Raton, FL: CRC Press; 2004.

3. Ramotowski RS. Lee and Gaensslen's Advances in Fingerprint Technology. 3rd ed. Boca Raton, FL: CRC Press; 2013.
4. Dafydd H, Williams G, Bleay S. Latent fingerprint visualization using a scanning Kelvin probe in conjunction with vacuum metal deposition. J Forensic Sci. 2014;59(1):211-218.

5. Bersellini C, Garofano L, Giannetto M, Lusardi F, Mori G. Development of latent fingerprints on metallic surfaces using electro polymerization processes. J Forensic Sci. 2001;46(4):871-877.

6. Qin G, Zhang M, Zhang Y, Zhu Y, Liu S, Wu W, Zhang X. Visualizing latent fingerprints by electrodeposition of metal nanoparticles. $J$ Electroanal Chem. 2013;693:122-126.

7. Williams SF, Pulsifer DP, Lakhtakia A, Shaler RC. Columnar-thin-filmassisted visualization of depleted sebaceous fingermarks on nonporous metals and hard plastics. J Forensic Sci. 2015;60(1):179-185.

8. Wightman G, O'Connor D. The thermal visualisation of latent fingermarks on metallic surfaces. Forensic Sci Int. 2011;204:88-96.

9. Dilag J, Kobus H, Yu Y, Gibson CT, Ellis AV. Non-toxic luminescent carbon dot/poly(dimethylacrylamide) nanocomposite reagent for latent fingermark detection synthesized via surface initiated reversible addition fragmentation chain transfer polymerization. Poly Int. 2015;64(7):884-891.

10. Singh K, Sharma S, Garg RK. Visualization of latent fingerprints using silica gel G: a new technique. Egyptian J Forensic Sci. 2013;3:20-25.

11. Jasuja OP, Singh G, Almog J. Development of latent fingermarks by aqueous electrolytes. Forensic Sci Int. 2011;207:215-222.

12. Jasuja OP, Singh K, Kumar P, Singh G. Development of latent fingermarks by aqueous electrolytes on metallic surfaces: further studies. $C a n$ Soc Forensic Sci J. 2015;48(3):122-136.

13. Silberberg MS. Chemistry-the Molecular Nature of Matter and Change. 3rd ed. New York, NY: McGraw-Hill; 2003, 158-162.

14. International Fingerprint Research Group (IFRG). Guidelines for the assessment of fingermark detection techniques. $J$ Forensic Ident. 2014;64(2):174-200.

15. Jasuja OP, Singh G, Sodhi GS. Development of latent fingerprints on compact disc and its effect on subsequent data recovery. Forensic Sci Int. 2006;156:237-241.
Research and Reports in Forensic Medical Science

\section{Publish your work in this journal}

Research and Reports in Forensic Medical Science is an international, peer-reviewed, open access journal publishing original research, reports, reviews and commentaries on all areas of forensic medical science. The manuscript management system is completely online and includes a

\section{Dovepress}

very quick and fair peer-review system. Visit http://www.dovepress.com/ testimonials.php to read real quotes from published authors. 